\title{
Synthesis, characterization and X-ray structural studies of four copper (II) complexes containing dinuclear paddle wheel structures
}

\author{
Samson Jegan Jenniefer and Packianathan Thomas Muthiah*
}

\begin{abstract}
Background: Various dinuclear copper (II) complexes with octahedral geometry have been reported. The majority of these complexes contain $\mathrm{N}$ containing aromatic rings as axial ligands. There are also a few cases where the solvent used in the reaction occupies the axial position of the dinuclear copper (II) complex. This may occur by planned synthesis or some times by serendipity. Here we report some four copper (II) complexes containing solvent and or $\mathrm{N}$ containing heterocyclic ring as the axial ligand.

Results: Four compounds, each containing dinuclear Copper (II) units (with the most robust, frequently occurring paddle wheel structures) were synthesized and characterised by single crystal $\mathrm{X}$-ray diffraction and by $\mathrm{IR}$ spectroscopy. The compounds $1 \& 2$ have the general formula $\mathrm{Cu}_{2}(\mathrm{RCOO}){ }_{4}(\mathrm{~L})_{2}[(\mathrm{for}(1) \mathrm{RCOO}=4$-Chloro Benzoate, $\mathrm{L}=$ Isopropanol; for $2 \mathrm{RCOO}=$ Benzoate, $\mathrm{L}=2$-Amino-4,6-dimethyl pyrimidine )] while $3 \& 4$ have the general formula, $\mathrm{Cu}_{2}(\mathrm{RCOO})_{4}(\mathrm{~S})_{2} \mathrm{Cu}_{2}(\mathrm{RCOO})_{4}(\mathrm{~L})_{2}[\mathrm{RCOO}=5$-Chloro-thiophene-2-carboxylate $\mathrm{L}=2$-Amino-4,6-dimethyl pyrimidine, for $3 \mathrm{~S}$ = ethanol; for $4 \mathrm{~S}=$ methanol ]. A wide range of hydrogen bonds (of the $\mathrm{O}-\mathrm{H} \ldots \mathrm{O}, \mathrm{N}-\mathrm{H} \ldots \mathrm{O}$ and $\mathrm{N}-\mathrm{H}$....N type) and $\pi-\pi$ stacking interactions are present in the crystal structures.

Conclusions: All compounds contain the dinuclear units, in which two Cu (II) ions are bridged by four syn, syn$\eta^{1}: \eta^{1}: \mu$ carboxylates, showing a paddle-wheel cage type with a distorted octahedral geometry. The compounds 1 \& 2 contain a single dimeric unit while $3 \& 4$ contain two dimeric units. The structures 3 and 4 are very interesting co-crystals of two paddle wheel molecules. Also it is interesting to note that the compounds $3 \& 4$ are isostructural with similar cell parameters. Both the compounds $3 \& 4$ differ in the solvent molecule coordinated to copper in one of the dimeric units. In all the four compounds, each of the copper dimers has an inversion centre. Every copper has a distorted octahedral centre, formed by four oxygen atoms (from different carboxylate) in the equatorial sites. The two axial positions are occupied by copper and the corresponding ligand.
\end{abstract}

Keywords: Paddle wheel structures, Cu (II) complexes, Supramolecular architectures, Carboxylates, Crystal structure

\section{Background}

Copper carboxylate complexes have properties of importance in various areas and accordingly have been extensively studied [1]. They are known to form different kind of structures even with same kind of ligand. The reasons for this diverse nature are the basic nature of ligand, steric factor, starting compound, solvents etc. They also have properties of special interest in the fields of biology and magnetism [2]. Since the first copper(II) carboxylate dimer ie copper(II) acetate hydrate $\left[\mathrm{Cu}_{2}\right.$

* Correspondence: tommtrichy@yahoo.co.in

School of Chemistry, Tiruchirappalli, 620024, Tamil Nadu, India
$\left.\left(\mathrm{MeCO}_{2}\right)_{4}\left(\mathrm{H}_{2} \mathrm{O}\right)_{2}\right]$ reported by van Niekerk and Schoening in 1953 [3], there have been reports of these kind of compounds. The dimeric copper (II) carboxylates $\left[\mathrm{Cu}_{2}\right.$ $(\mathrm{RCOO})_{4} \mathrm{~L}_{2}$ ] are found to contain two or more antiferromagnetically coupled metal centres [4-7] and their magneto-structural correlation has been studied extensively [8]. Halogenated 2-thiophene carboxylic acids are used as building blocks for a new family of insecticides which also possess low mammalian toxicity [9]. The metal complexes formed by the interaction of thiophene carboxylic acid show an elevation in their biological activity $[10,11]$. It is also used in study of biological systems involving microbial degradation studies of sulphur 
containing compounds $[12,13]$. In contrast, in this regard, the use of carboxylic acid ligands with thiophene skeleton to construct $\mathrm{Cu}$ (II) - carboxylate compounds has been less investigated to date. Pyrimidine and aminopyrimidine derivatives are biologically very important compounds as they are components of nucleic acids [14]. The carboxylate group exhibits a variety of coordination behaviour displaying non identical bonding modes towards metal cations, such as monodentate and chelate, as well as $\eta^{1}: \eta^{2}: \mu^{2}$ bridging ligands in syn, syn, syn, anti, and anti,anti conformations $[15,16]$. In all the compounds $\mathbf{1 - 4}$ the synsyn arrangement (Figures 1, 2, 3, 4) of carboxylate groups keeps the copper ions close enough making the possibility of copper-copper interaction [17]. The most important feature of the six fold coordinated copper complex is the close approach of the $\mathrm{Cu}-\mathrm{Cu}$ distance $[16,18]$. In this frequently occurring octahedral geometry each of the copper atoms forms (in addition to the bonds from four oxygens that lies in the mean plane) a bond with copper atom and the corresponding axial ligand or solvent molecule. The co-crystals of inorganic complex with another inorganic complex are not common [19]. Recently there have been reports of co-crystal of two or more inorganic neutral complexes, there are also reports each neutral part having paddle wheel structure [19-22]. In this paper we report the synthesis and crystal structures of four copper (II) complexes with amino pyrimidine and different substituted carboxylate ligands which also include two isostructural, co-crystals of two inorganic neutral complexes.

\section{Results and discussion}

\section{IR spectra}

The FT-IR spectra of the complex 1-4 were recorded in a $\mathrm{KBr}$ pellet. The IR spectra of $\mathbf{1 - 4}$ gives the values of the asymmetric $v_{\text {asym }}\left(\mathrm{COO}^{-}\right)$, symmetric $v_{\text {sym }}\left(\mathrm{COO}^{-}\right)$ and $\Delta v$ [the difference between $\left(v_{\text {asym }}\left(\mathrm{COO}^{-}\right)\right.$and $v_{\text {sym }}$ $\left.\left(\mathrm{COO}^{-}\right)\right]$. This can indicate the coordination mode of the $\left(\mathrm{COO}^{-}\right) . \Delta v$ for compounds $\mathbf{1 - 4}$ are $183 \mathrm{~cm}^{-1}$, $208 \mathrm{~cm}^{-1}, 162 \mathrm{~cm}^{-1}, 162 \mathrm{~cm}^{-1}$ respectively. This result indicates the symmetrical bridging coordination mode of the carboxylate (syn, syn- $-\eta^{1}: \eta^{1}: \mu^{2}$ ) giving rise to a paddlewheel type structure [16,23-26]. For compounds 1, 3, and 4 the difference was all less than $200 \mathrm{~cm}-1$, which indicated the symmetrical bridging coordination mode of the carboxylate. However, the difference between $v_{\text {asym }}(\mathrm{COO}-)$ and $v_{\text {sym }}$ (COO-) for compound 2 was greater than $200 \mathrm{~cm}-1$. The hydrogen bond between N3-H6-O1 renders the symmetrical carboxylate asymmetrical, which is attributed to

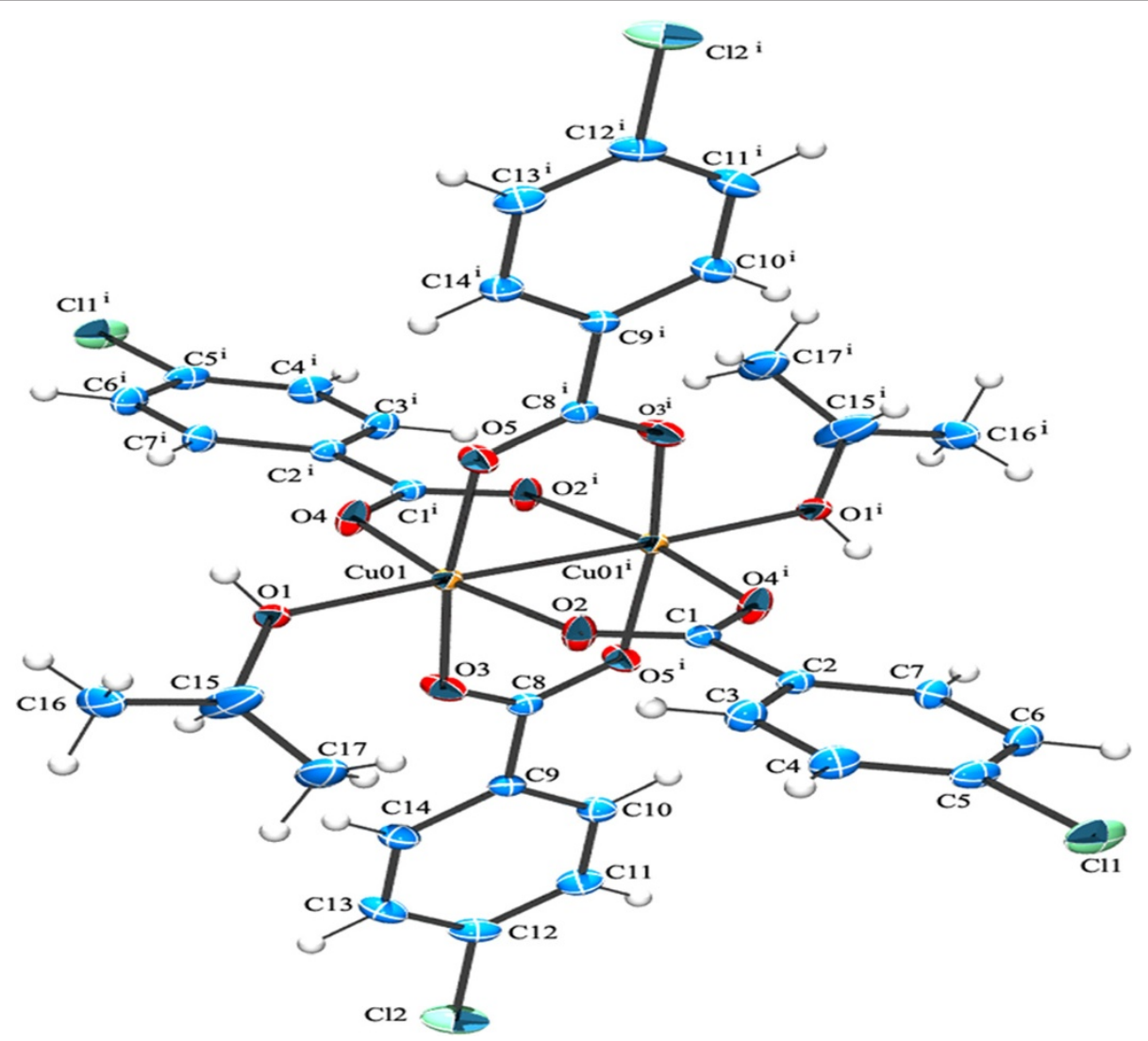

Figure 1 ORTEP view of compound (1) showing the atom-numbering scheme. Displacement ellipsoids are drawn at the 50\% probability level and $\mathrm{H}$ atoms are shown as small spheres of arbitrary radii [symmetry code a: 1-x,1-y,1-z]. 


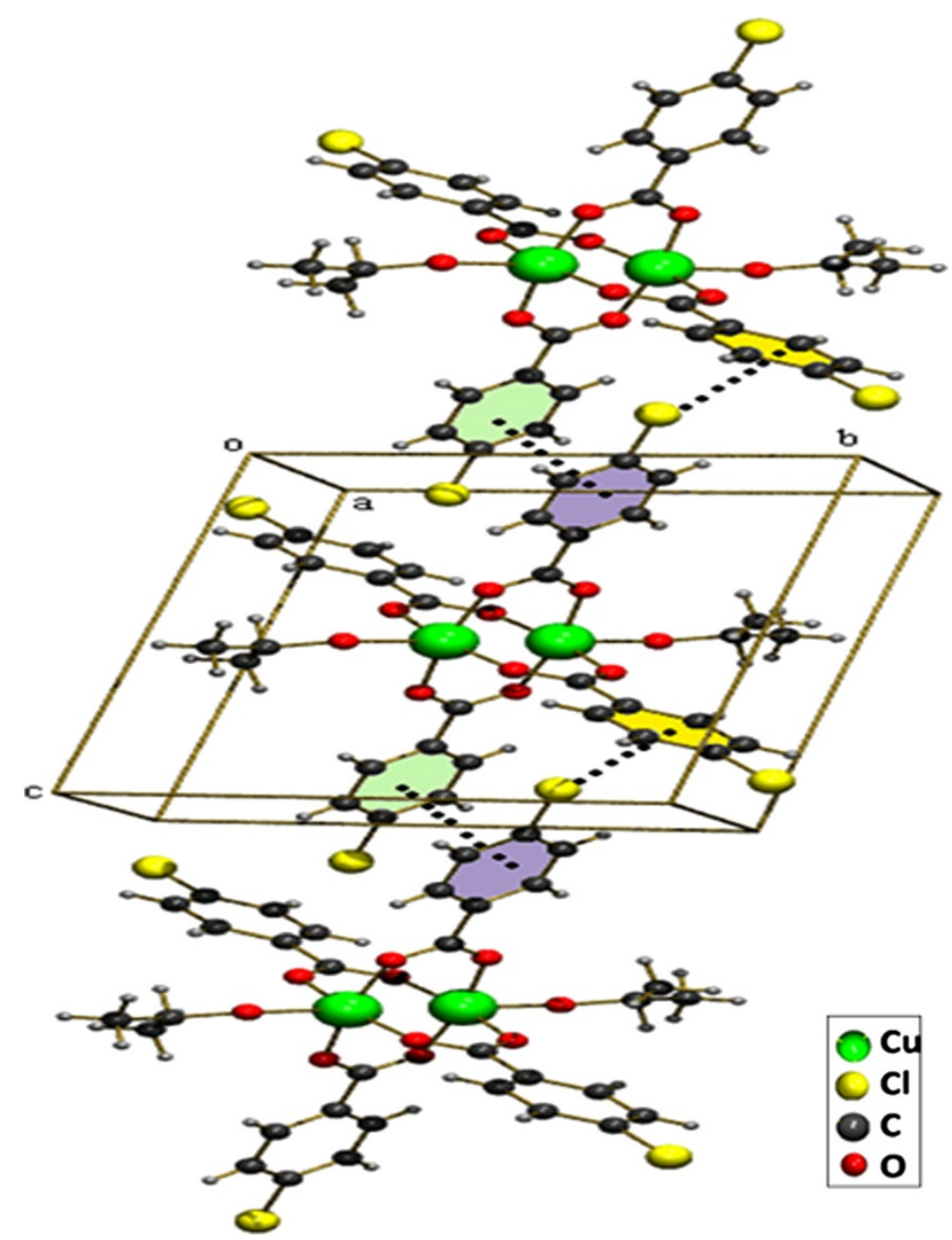

Figure 2 Formation of $2 \mathrm{D}$ sheet due to the $\pi-\pi$ stacking and $\mathrm{Cl}-\pi$ interactions between 4-chloro benzoate molecules.

the large difference between $v_{\text {asym }}(\mathrm{COO}-)$ and $v_{\text {sym }}(\mathrm{COO}-)$ for compound 2 [27]. The IR spectra of $\mathbf{3}$ and $\mathbf{4}$ are essentially similar. In the IR spectra of $\mathbf{2 - 4}, v_{\text {asym }}\left(\mathrm{COO}^{-}\right)$is split into two components, which is due to the hydrogen bonding of the bridged carboxylate ligand [28].

\section{Crystal structure}

Crystal structure description of

$$
\left[\mathrm{Cu}_{2}\left(\mathrm{ClC}_{6} \mathrm{H}_{4} \mathrm{COO}\right)_{4}(\text { Isopropanol })_{2}\right]
$$

The title compound $\left.\left[\mathrm{Cu}_{2}\left(\mathrm{ClC}_{6} \mathrm{H}_{4} \mathrm{COO}\right)_{4} \text { (Isopropanol }\right)_{2}\right]$, 1 was obtained by serendipity while trying to crystallize mixed ligand complex involving 2-Amino-4,6-dimethyl pyrimidine in isopropanol solvent. The molecular structure of $\mathbf{1}$ is more comparable with copper (II) acetate hydrate. Each copper atom is six coordinated in an octahedral fashion by four equatorial oxygen atoms belong to four carboxyl groups (Table 1) with $\mathrm{Cu}-\mathrm{O}_{\text {eq }}$ distance which ranges from $1.959(2)$ to $1.965(2) \AA$. The O atoms at the apical positions belong to isopropanol. The $\mathrm{Cu}-\mathrm{Cu}$ distance is small hence it is also considered as a bond. An ORTEP view of the dimer is shown in (Figure 1). $\pi-\pi$ stacking interaction is found between two 4-chloro benzoate rings (C2, C3, C4, C5, C6, C7) (Figure 5) along the a axis: d(cg-cg) $3.8105 \AA$. $\mathrm{Cl}-\pi$ interaction ( $\mathrm{Cl}$. . .cg distance, $3.7701 \AA$ ) is found in between $\mathrm{Cl}$ of the 4-chloro benzoate ring and the six member ring comprised of (C9, C10, C11, C12, C13, C14) along the $\mathrm{c}$ axis (Figure 5). This leads to a 2D sheet (Figure 2).

$$
\text { Crystal structure of }\left[\mathrm{Cu}_{2}\left(\mathrm{C}_{6} \mathrm{H}_{5} \mathrm{COO}\right)_{4}(\mathrm{AMPY})_{2}\right]
$$

The structure consists of the centrosymmetric dimeric molecule $\left[\mathrm{Cu}_{2}\left(\mathrm{C}_{6} \mathrm{H}_{5} \mathrm{COO}\right)_{4}(\mathrm{AMPY})_{2}\right],(\mathrm{AMPY}=2$-Amino 


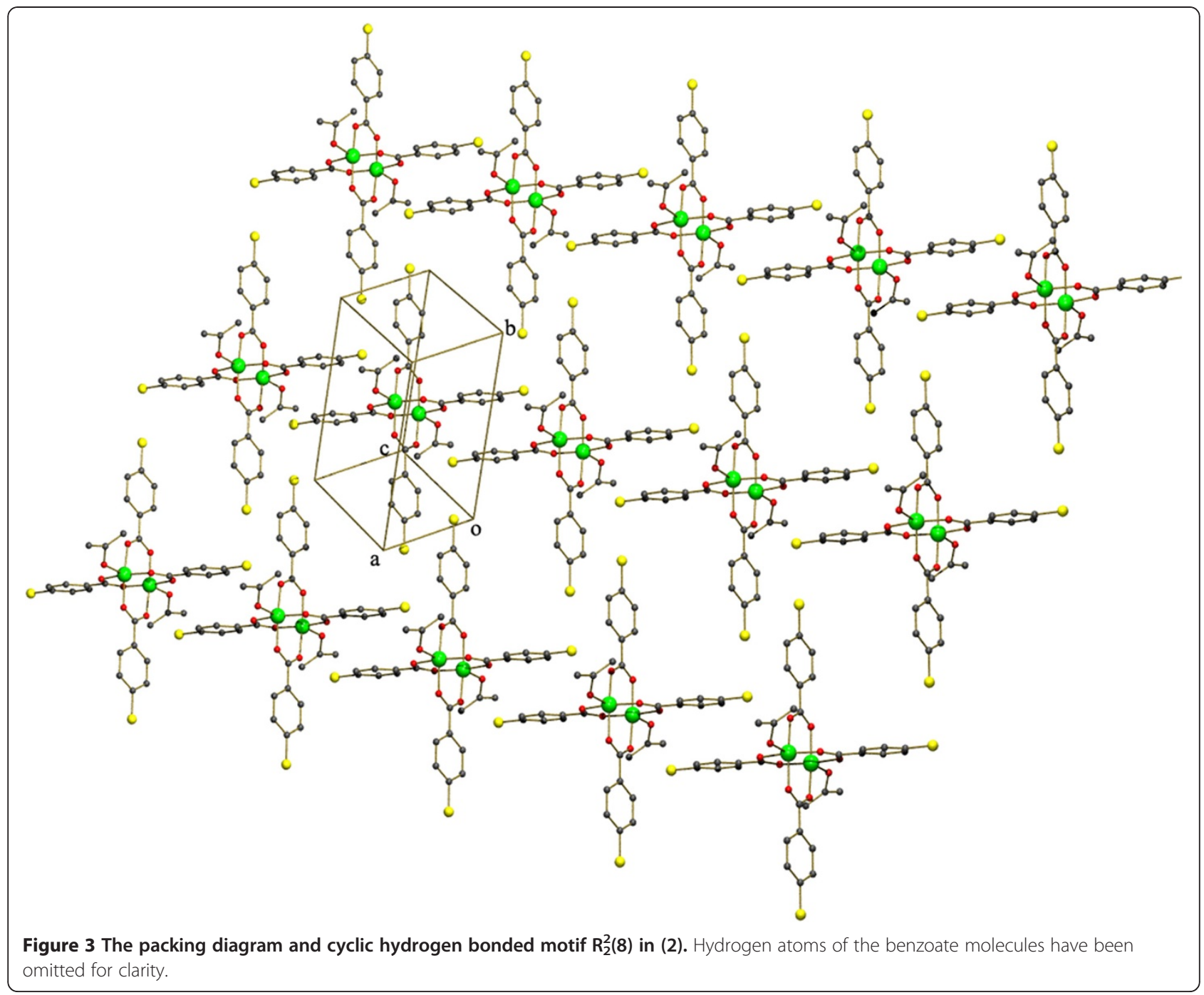

-4,6-dimethyl pyrimidine) in which two copper(II) atoms are bridged via four benzoate anions thus forming a square base of four oxygen atoms (Table 1) around each copper (the average $\mathrm{Cu}-\mathrm{O}$ distances lie from 1.9474(16) $1.9655(16) \AA$ ). The apical positions of the octahedral coordination polyhedron are occupied by the $\mathrm{N}$ of a AMPY molecule (the $\mathrm{Cu} 1$-N1 distance being 2.2724(18) $\AA$ and the $\mathrm{Cu}$ atom of the dimer). The $\mathrm{Cu}-\mathrm{N}_{\mathrm{ax}}$ distance in unsubstituted pyrimidine containing copper complexes lies in range of $(2.033$ (4) $\AA$ and 2.025 (4) $\AA$ ) $[29,30]$. The copper atoms are displaced from the respective basal planes towards the apical nitrogen atoms by $0.176 \AA$, and the $\mathrm{Cu}-\mathrm{Cu}$ separation within the dimer was found to be 2.6691(5) $\AA$, is typical for the dinuclear paddle wheel type of copper coordination compounds. An ORTEP view of the dimer is shown in (Figure 6). The amino group of the axial ligand interacts with the pyrimidine nitrogen of the next molecule through a pair of $\mathrm{N}-\cdots-\mathrm{H}-\mathrm{N}$ hydrogen bonds, forming a cyclic hydrogen bonded motif with graph set notation, $R_{2}^{2}(8)$ (Figures 3,7 ). The inter molecular $\mathrm{N}-\mathrm{H}-\mathrm{N}$ hydrogen bonds are found in between N3H6a- - - N2 [symmetry code a: (1-x,1-y,-z)]. Intra molecular hydrogen bonds are found in between N3 -H6b- - -O1 [symmetry code b: $(1 / 2-\mathrm{x},-1 / 2+\mathrm{y}, 1 / 2-\mathrm{z})]$ and $\mathrm{C} 19-\mathrm{H} 22 \mathrm{c}-$ - -O2 [symmetry code c: $(-1 / 2+x, 1 / 2-y,-1 / 2+z)]$.

$$
\begin{aligned}
\text { Crystal structure of } & {\left[\mathrm{Cu}_{2}(5-\mathrm{TPC})_{4}(\text { ethanol })_{2}\right] } \\
& {\left[\mathrm{Cu}_{2}(5-\mathrm{TPC})_{4}(\mathrm{AMPY})_{2}\right] }
\end{aligned}
$$

The compound 3 is a co-crystal and it contains two neutral inorganic units with the dimeric paddle wheel structure. The crystal structure of 3 consists of two centrosymmetric dimeric units $\left[\mathrm{Cu}_{2}(5-\mathrm{TPC})_{4}(\text { ethanol })_{2}\right]$ $\left[\mathrm{Cu}_{2}(5-\mathrm{TPC})_{4}(\mathrm{AMPY})_{2}\right]$ (5-TPC = 5-Chloro-thiophene2-carboxylate). In dimeric unit (i) two copper (II) atoms are bridged via four thiophene carboxylate anions while the apical positions are occupied by ethanol molecule 


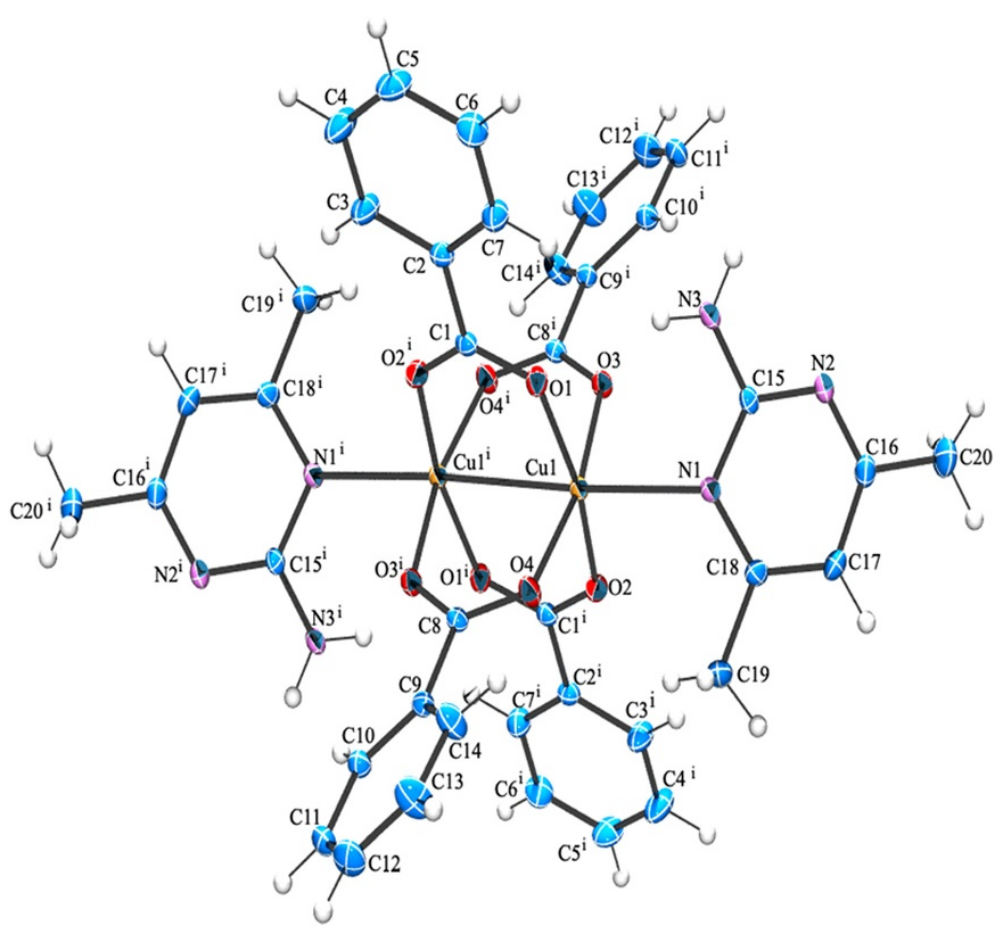

Figure 4 ORTEP view of compound (3) showing the atom-numbering scheme. Displacement ellipsoids are drawn at the 50\% probability level and $\mathrm{H}$ atoms are shown as small spheres of arbitrary radii [symmetry code: $\mathrm{a}(-\mathrm{x}, 1-\mathrm{y},-\mathrm{z})]$ [symmetry code: $\mathrm{b}(1-\mathrm{x},-\mathrm{y}, 1-\mathrm{z})]$.

and $\mathrm{Cu}$ atom of the same dimer (Table 1). In dimeric unit (ii) two copper (II) atoms are bridged via four thiophene carboxylate anions while the apical positions are occupied by AMPY molecule and $\mathrm{Cu}$ atom, thus forming a square base of four oxygen atoms around each copper. An ORTEP view of compound 3 is shown in (Figure 4). The average $\mathrm{Cu}-\mathrm{O}$ distance in dimer (i) lies from 1.952(8) to 1.964(10) $\AA$ and the average $\mathrm{Cu}-\mathrm{O}$ distance in dimer (ii) lies from 1.950(9) to 1.974(9) $\AA$. The axial $\mathrm{Cu}-\mathrm{O}$ distance in dimer (i) is 2.170 (9) $\AA$ while the $\mathrm{Cu}-\mathrm{N}$ distance is 2.311(11) $\AA$ in dimer (ii) is [less than that of 2]. Intra molecular interactions are found in between N3-H3a- - -O8 and C27-H27a- - -O6 [symmetry code a: $(-x, 1-y,-z)]$ (Figure 8$)$. The dimeric unit (i) and (ii) are linked by $\mathrm{N}-\mathrm{H}-$ - - O hydrogen bond between N3- H3b- - -O1 [symmetry code b:(1-x,-y,1-z)] (Figure 8). Additional stabilization is found through $\pi-\pi$ stacking interactions between nearly parallel coordinated 5-TPC five member rings $[S(4), C(19), C(20), C(21), C(22) \& S(1)$,
$\mathrm{C}(2), \mathrm{C}(3), \mathrm{C}(4), \mathrm{C}(5)]$ : d(cg-cg) 3.798(7) $\AA$. Another $\pi-\pi$ stacking interactions are found between $[S(3), C(14), C$ (15),C(16),C(17) \& $S(3), C(14), C(15), C(16), C(17)]$ : d(cgcg) 3.693(9) $\AA$. This $\mathrm{N}-\mathrm{H}$... O hydrogen bonds by the AMPY molecules lead to a 1D chain as in 2 leading to 2D sheets (Figure 9). Two of these sheets are stacked together by $\pi-\pi$ stacking interactions (Figure 10).

$$
\begin{gathered}
\text { Crystal structure of }\left[\mathrm{Cu}_{2}(5-\mathrm{TPC})_{4}(\text { methanol })_{2}\right](4) \\
{\left[\mathrm{Cu}_{2}(5-\mathrm{TPC})_{4}(\mathrm{AMPY})_{2}\right]}
\end{gathered}
$$

As compound $\mathbf{3}$, compound $\mathbf{4}$ is also a co-crystal and it contains two neutral inorganic units with the dimeric paddle wheel structure. Compounds $\mathbf{3}$ and $\mathbf{4}$ are isostructural. Different from 3, complex 4 exhibits a methanol solvent coordinated to copper ion in the place of ethanol. In the compound $\mathbf{4}$ there are two dimeric units with an inversion centre located between each of the copper ions $\left[\mathrm{Cu}_{2}(5-\mathrm{TPC})_{4}(\text { methanol })_{2}\right]\left[\mathrm{Cu}_{2}(5-\mathrm{TPC})_{4}\right.$

Table 1 Representing the dimers in compounds (1-4)

\begin{tabular}{lllllll}
\hline Ligands & $\mathbf{1}$ & $\mathbf{2}$ & $\mathbf{3}$ & $\mathbf{4}$ & \\
& Dimer & Dimer & Dimer (i) & Dimer ( ii) & Dimer (i) & Dimer ( ii) \\
\hline RCOO & 4-Chloro Benzoate & Benzoate & 5-TPC & 5-TPC & 5-TPC & A-TPC \\
L & Isopropanol & AMPY & & AMPY & Methanol \\
$S$ & & & Ethanol & & MPY \\
\hline
\end{tabular}

General formula for (1) and (2) $\mathrm{Cu}_{2}(\mathrm{RCOO})_{4}(\mathrm{~L})_{2}$, general formula for (3) and (4) $\mathrm{Cu}_{2}(\mathrm{RCOO})_{4}(\mathrm{~S})_{2} \mathrm{Cu}_{2}(\mathrm{RCOO})_{4}(\mathrm{~L})_{2}$. 


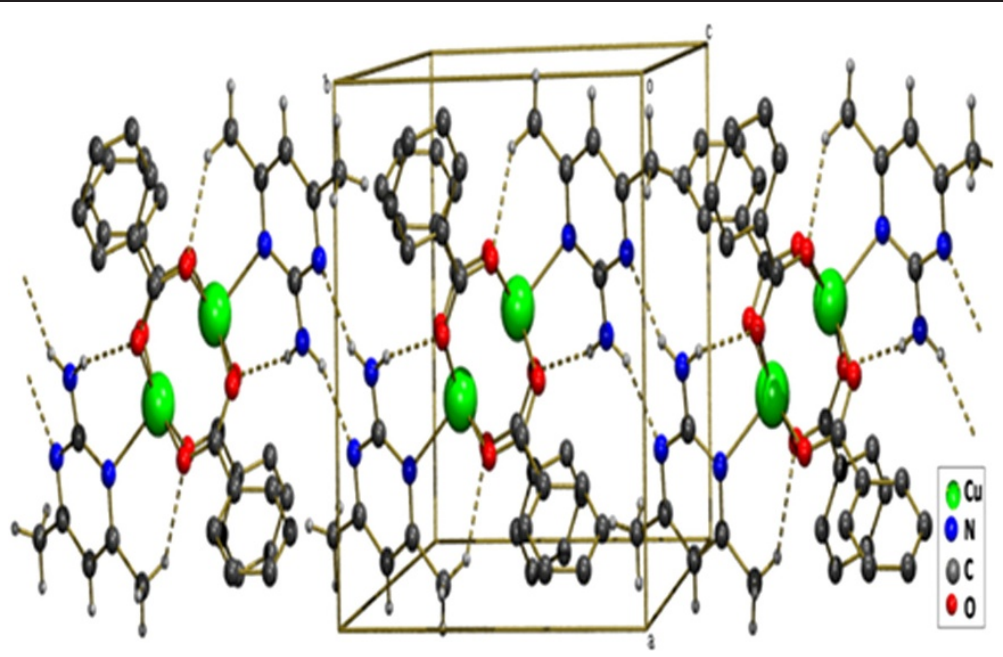

Figure 5 Showing the packing diagram of (1) and the $\pi-\pi$ stacking and $\mathrm{Cl}-\pi$ interactions between 4-chloro benzoate molecules.

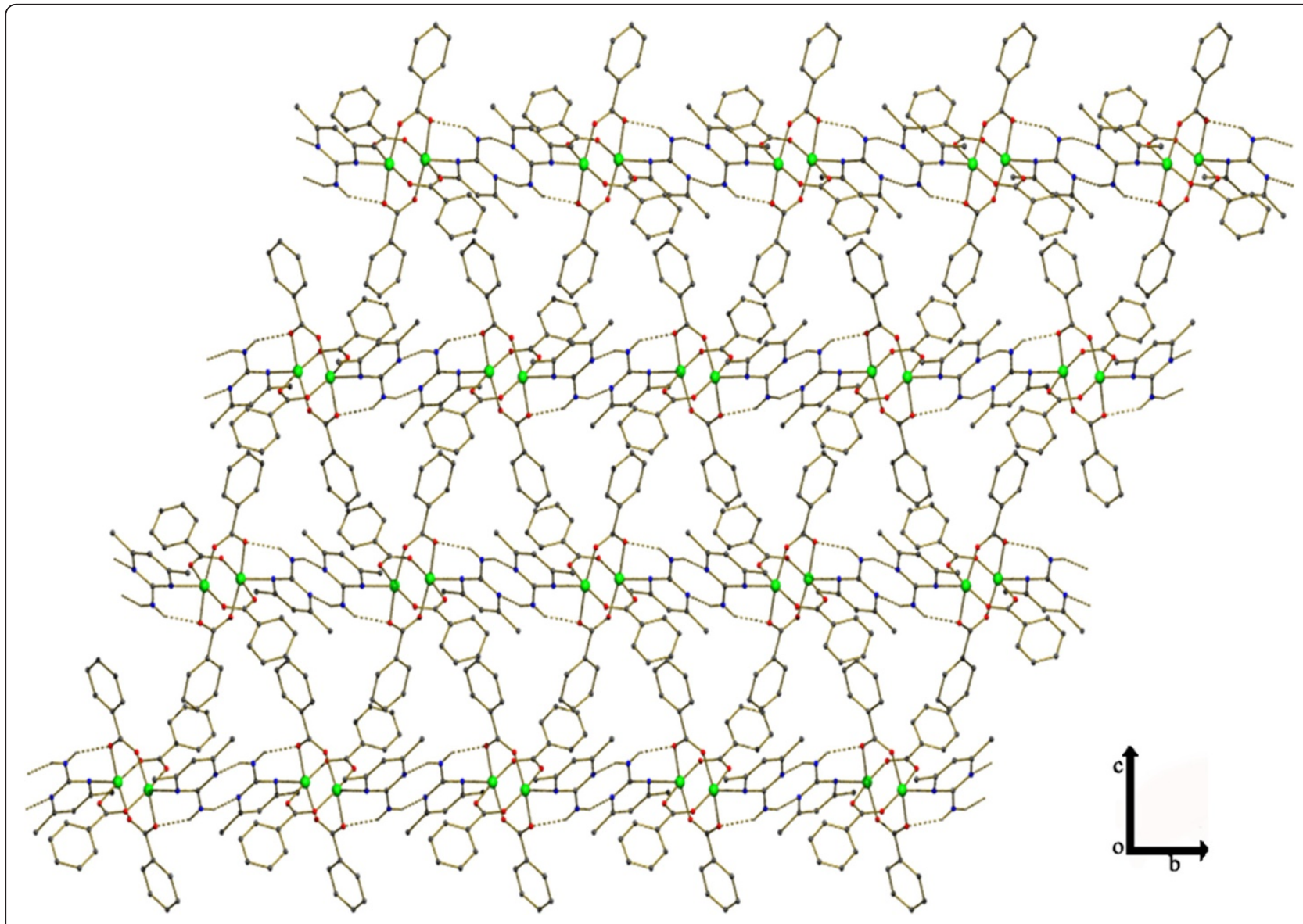

Figure 6 ORTEP view of compound (2) showing the atom-numbering scheme. Displacement ellipsoids are drawn at the 50\% probability level and $\mathrm{H}$ atoms are shown as small spheres of arbitrary radii [symmetry code: a $(1-x, 1-y,-z)]$. 


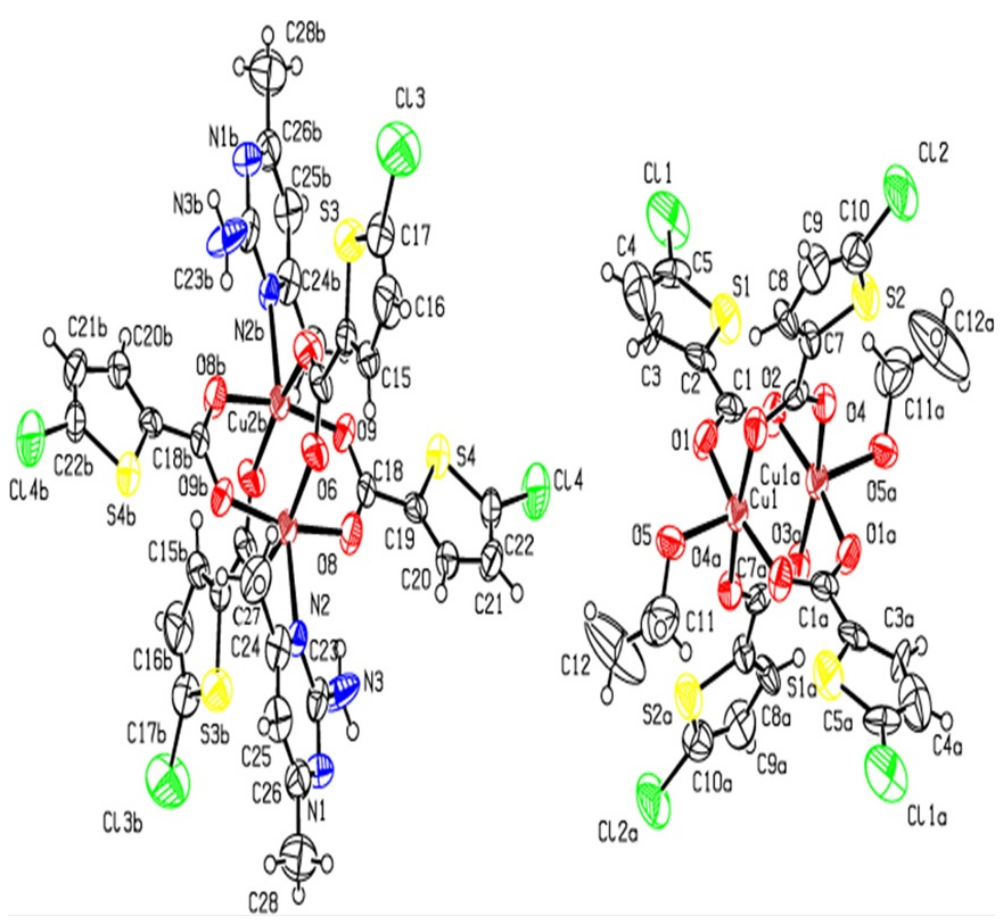

Figure 7 A view of supramolecular chains formed by $\mathrm{N}-\mathrm{H} \cdots \mathrm{O}$ hydrogen bonds.

$(\mathrm{AMPY})_{2}$ ]. In dimeric unit (i) two copper (II) atoms are bridged via four thiophene carboxylate anions while the apical positions are occupied by methanol molecule and $\mathrm{Cu}$ atom of the same dimer. In dimeric unit (ii) two copper (II) atoms are bridged via four thiophene carboxylate anions while the apical positions are occupied by AMPY molecule (Table 1) and $\mathrm{Cu}$ atom of the same dimer, thus forming a square base of four oxygen atoms around each copper. An ORTEP view of the structure is shown in (Figure 11). The average $\mathrm{Cu}-\mathrm{O}$ distance in dimer (i) is $1.948(7)-1.980(6) \AA$ and the average $\mathrm{Cu}-\mathrm{O}$ distance in dimer (ii) is 1.959(6)- 1.974(6) $\mathrm{A}$. The axial $\mathrm{Cu}-\mathrm{O}$

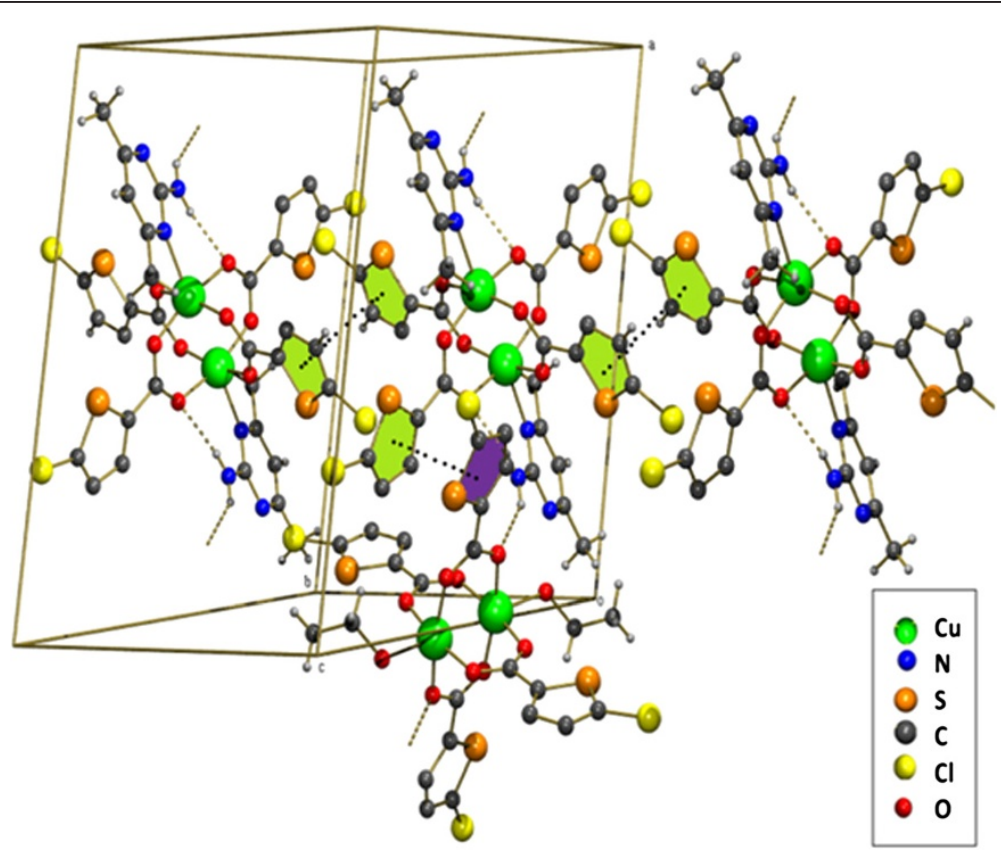

Figure 8 The supramolecular architecture in compound (3). The H atoms of 5-TPC rings are omitted for clarity. 


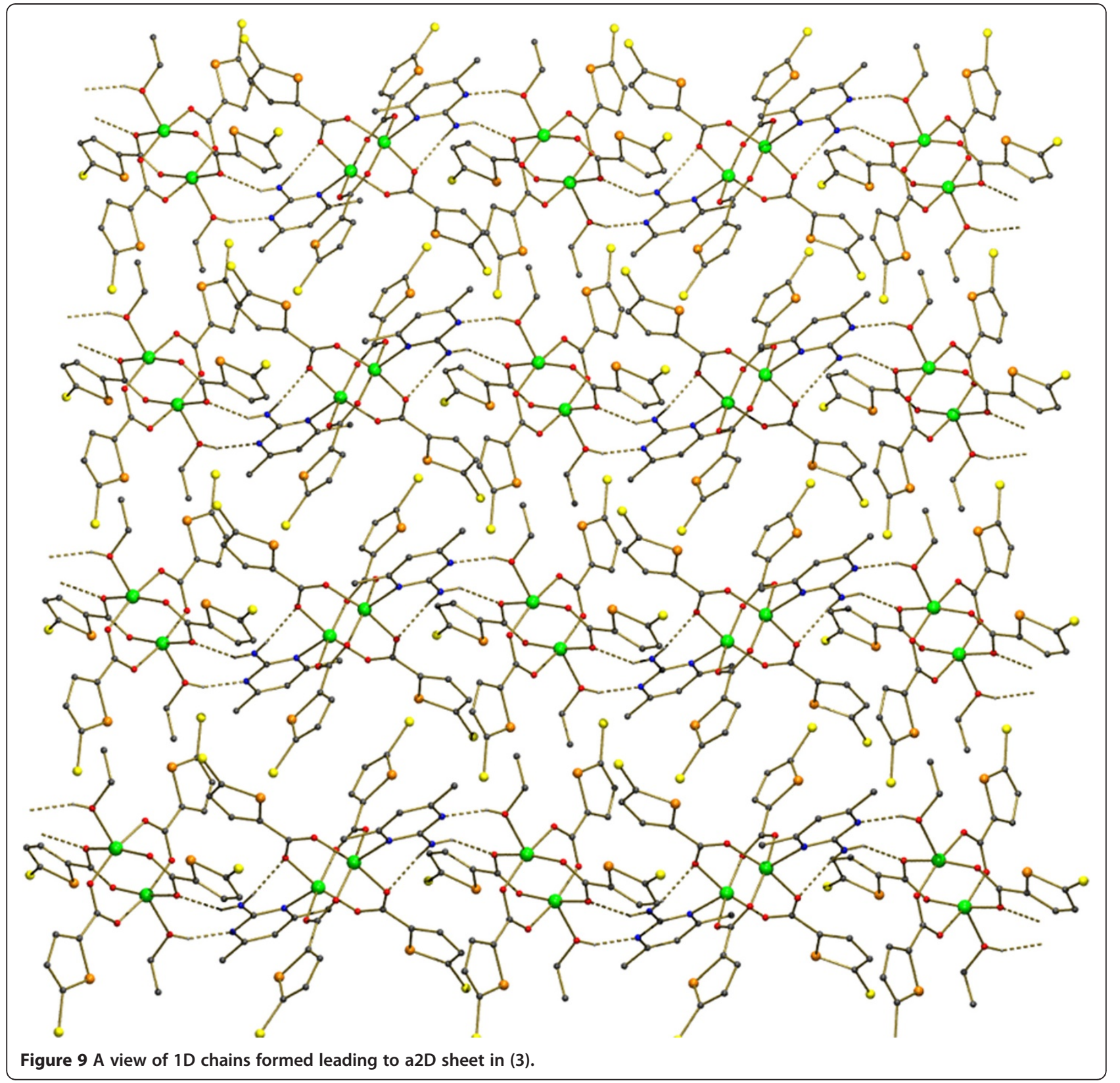

distance 2.155(6) $\AA$ in dimer (i) is slightly less than that compared to 3, while the $\mathrm{Cu}-\mathrm{N}$ distance $2.301(7) \AA$ in dimer (ii) is lesser than as compared to 2 and 3 . The $\mathrm{C}$ $\mathrm{H}$. . . O hydrogen bonds are observed inbetween C26 - H26a - - -O7 [symmetry code a:-x,1-y,1-z ]. The H3b attached to the $\mathrm{NH}_{2}$ of the AMPY is involved in bifurcated hydrogen bonding N3-H3b- - -O8 [symmetry code b:1-x,2-y,-z ] and N3 -H3b- - -O9 [symmetry code b:1-x,2-y,-z ]. The dimers (i) and (ii) are linked by N3-H3a- - -O4 hydrogen bond [symmetry code a:- $x, 1-y, 1-z]$ (Figure 12). Two $\pi-\pi$ stacking are observed between nearly parallel coordinated 5-TPC five member rings [S(3),C(13), $\mathrm{C}(14), \mathrm{C}(15), \mathrm{C}(16$ and $\mathrm{S}(2), \mathrm{C}$ (7), $C(8), C(9), C(10)]$ : d(cg-cg) 3.801(2) ̊. $\pi-\pi$ stacking are observed between nearly parallel coordinated 5-TPC five member rings $[S(4), C(18), C(19), C(20), C(21)$ and $S(4), C(18)$, $C(19), C(20), C(21)]$ : d(cg-cg) 3.668(6) $\AA$. A view of the packing is shown in (Figure 12).

\section{Comparison of geometrical parameters}

There is a relationship between $\mathrm{Cu}--\mathrm{Cu}$ distance and the plane from which the $\mathrm{Cu}$ moves from the mean square base made up of four oxygen of the benzoate. It has been proposed after analysis of various dimeric Copper (II) acetate dihydrate analogue complexes [1]. As there is increase in $\mathrm{Cu}-$ - $\mathrm{Cu}$ distance within the dimer, there is greater deviation of the $\mathrm{Cu}$ atom from the mean 

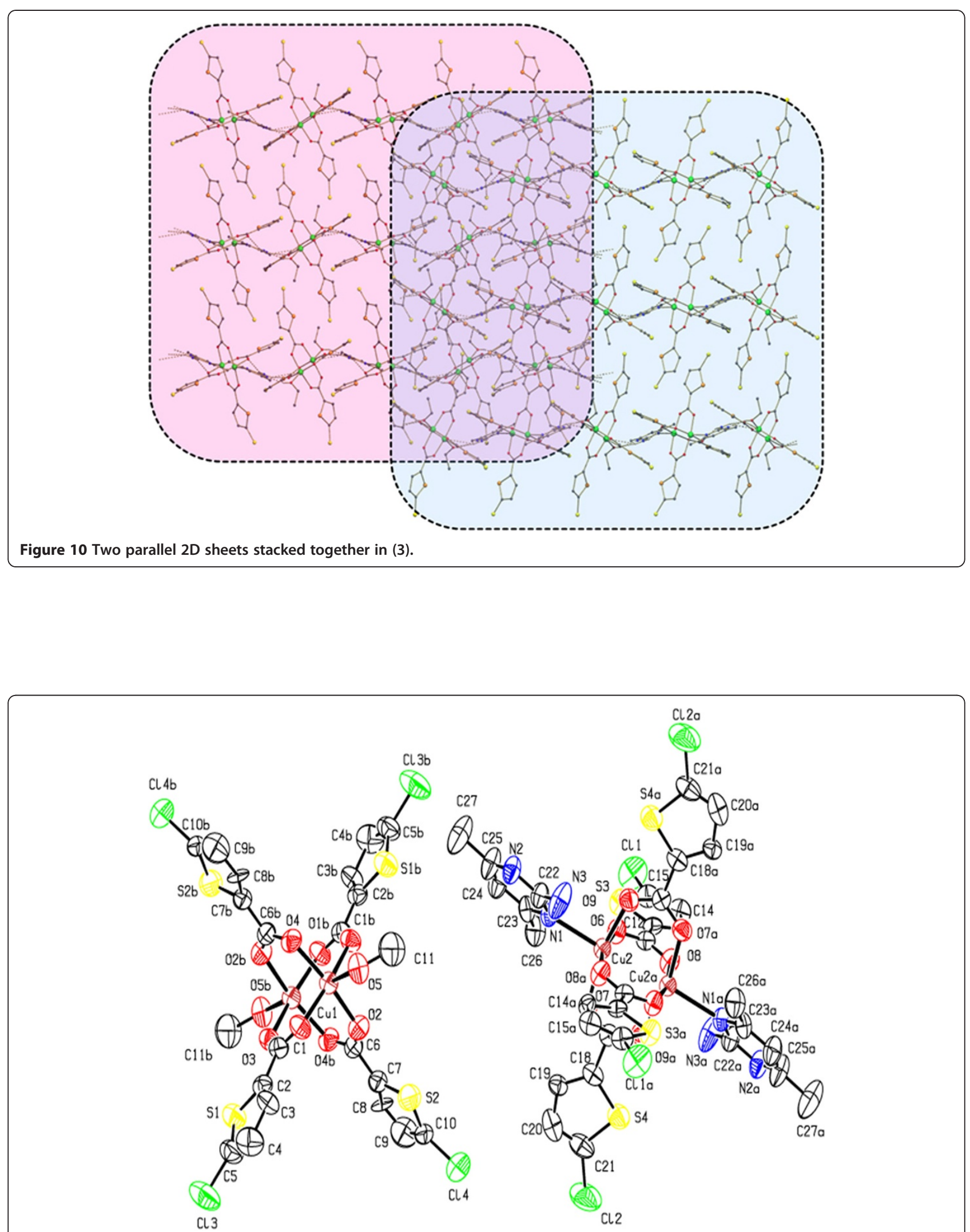

Figure 11 ORTEP view of compound (4) showing the atom-numbering scheme. Displacement ellipsoids are drawn at the 50\% probability level and $\mathrm{H}$ atoms are omitted for clarity [symmetry code $a:-x, 1-y, 1-z$, ] [symmetry code b:1-x,2-y,-z]. 


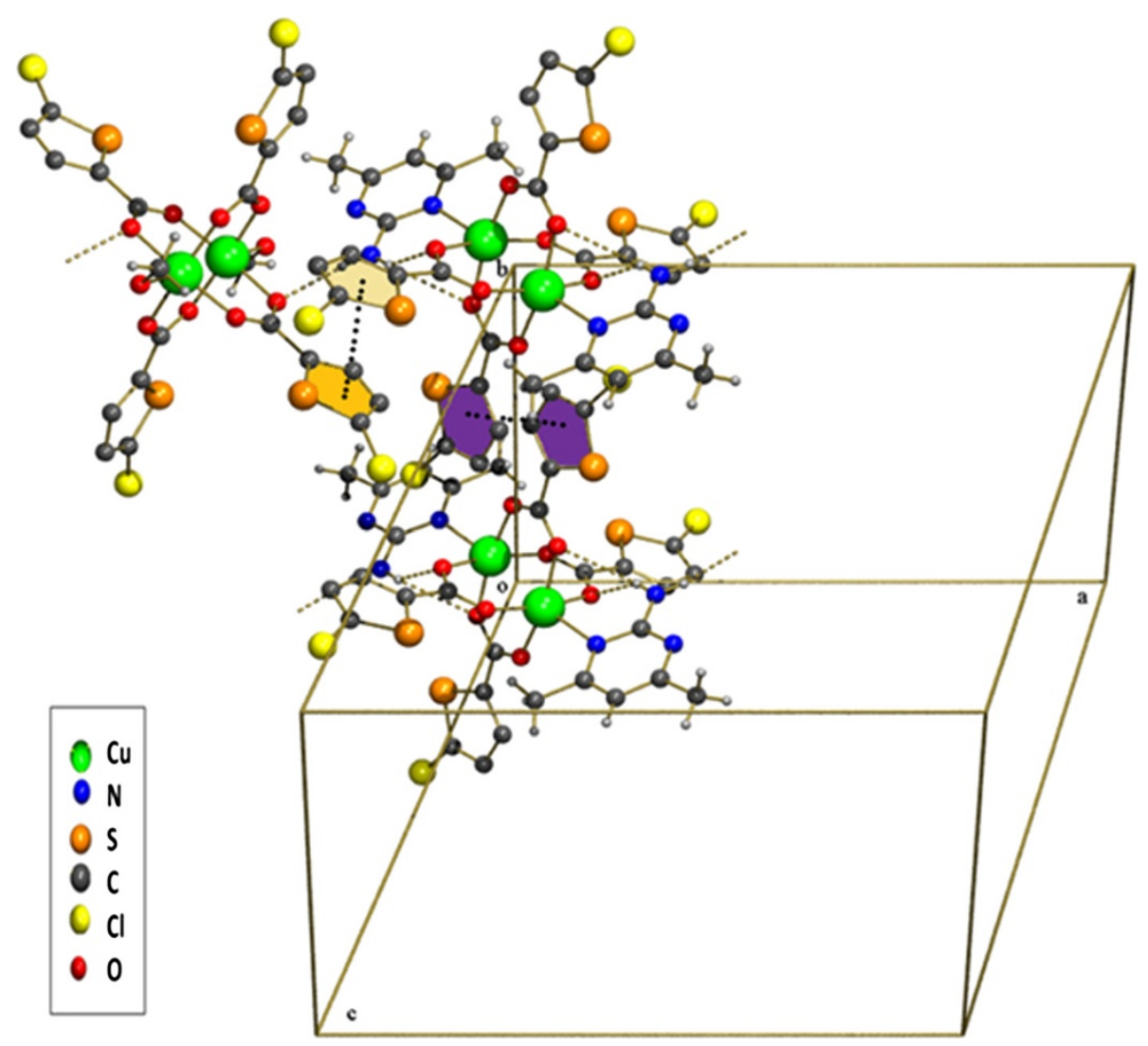

Figure 12 A view of packing diagram (4) and the $\pi-\pi$ stacking interactions between the two nearly parallel 5-TPC rings. Hydrogen of 5TPC are removed for clarity.

O4 plane .It has also been studied that whenever there are substituent's on the 2-and/or 6-position of the axial pyridine ligand, the $\mathrm{Cu}-\mathrm{N}$ distance is relatively long [31]. Based on these and extending these ideas to pyrimidine ligands we have tabulated the corresponding bond lengths and bond angles for all copper complexes (Table 2). In the dimeric units of $\mathbf{3}$ and $\mathbf{4}$ it can be noted that where ever there is an axial pyrimidine ligand, there is higher deviation of copper from the mean plane. Correspondingly we can note from the (Table 2) that when-

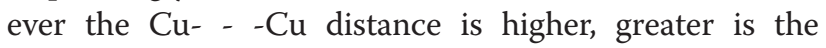
deviation of copper from the mean plane. From the (Table 2) it can be found that the $\mathrm{Cu}-\mathrm{N}$ distance is high compared to that of $\mathrm{Cu}-\mathrm{N}$ distances in similar systems containing un substituted pyrimidine ligands [29,30]. The increase in $\mathrm{Cu}$... Cu distance and $\mathrm{Cu}-\mathrm{N}$ distance in systems containing substituted pyrimidine ligands $\mathbf{3 , 4}$ may be due to steric and electronic factor of the apical ligand. It is found that such position of the ligand is very important as it strongly influences the $\mathrm{Cu}-\mathrm{Cu}$ distances and also the carboxylate cage. The geometry around each $\mathrm{Cu}(\mathrm{II})$ ion can be best described as a slightly distorted octahedron showing tetracarboxylate type $\mathrm{Cu}_{2-}$
$\left(\mathrm{RCO}_{2}\right)_{4}$ unit. The $\mathrm{Cu}-\mathrm{Cu}$ distance in compounds 1-4 lies in the range of (2.6143(5)- 2.758(3) $\AA$ ), which is observed within the normal range for dinuclear paddlewheel units in the structures of $\mathrm{Cu}(\mathrm{II})$ carboxylate complexes [16,32-38]. The axial $\mathrm{N}-\mathrm{Cu}-\mathrm{Cu}-\mathrm{N}$ distance and $\mathrm{O}-\mathrm{Cu}-\mathrm{Cu}-\mathrm{O}$ distances; are almost same as that of $(\mathrm{Cu}-\mathrm{Cu}+\mathrm{Cu}-\mathrm{N})$ and $(\mathrm{Cu}-\mathrm{Cu}+\mathrm{Cu}-\mathrm{O})$ distances respectively [Table 2]. This shows that the shortening of $\mathrm{Cu}-\mathrm{Cu}$ distance is compensated by the axial $\mathrm{Cu}-\mathrm{N}$ or $\mathrm{Cu}-\mathrm{O}$ elongation. Thus we can conclude that there is an inversely proportional relationship between $\mathrm{Cu}-\mathrm{Cu}$ and the $\mathrm{Cu}-\mathrm{L}$ bond lengths, respectively. In copper carboxylate dimers if the $\mathrm{Cu}-\mathrm{Cu}$ bond is longer shorter will be $\mathrm{Cu}-\mathrm{L}$ distance and vice versa.

\section{Experimental}

\section{Materials and methods}

Commercial starting materials were used without further purification. 5-Chloro thiophene 2- carboxylic acid (Hoechst Aktiengesellschaft), methanol and $\mathrm{Cu}(\mathrm{NO})$ 3. $6 \mathrm{H}_{2} \mathrm{O}$ (Qualigens, India) and ethanol (Changhhu Yangyuan chemicals, China) were used. IR spectra of the complex in region $400-4000 \mathrm{~cm}^{-1}$ were recorded as 
Table 2 Comparison of geometric parameters ( $\AA$ ) for some copper(II) benzoate dimers of compounds 1-4

\begin{tabular}{|c|c|c|c|c|c|c|c|c|c|c|c|}
\hline & & $\begin{array}{l}\text { Equtorial O-Cu-O } \\
\text { distance }(\AA \AA)\end{array}$ & $\begin{array}{l}\text { Axial Cu-O } \\
\text { distance (Å) }\end{array}$ & $\begin{array}{l}\text { Axial Cu-N } \\
\text { distance (Å) }\end{array}$ & $\begin{array}{l}\mathrm{Cu} \text { - deviation from } \\
\text { mean plane }(\AA)\end{array}$ & $\begin{array}{l}\text { Cu-Cu } \\
\text { distance (Å) }\end{array}$ & $\begin{array}{l}\mathrm{O}-\mathrm{Cu}-\mathrm{O} \text { equatorial } \\
\text { bond angle }\left({ }^{\circ}\right)\end{array}$ & $\begin{array}{l}\mathrm{O}-\mathrm{Cu}-\mathrm{O} \text { axial } \\
\text { bond angle }\left(^{\circ}\right)\end{array}$ & $\begin{array}{l}\mathrm{O}-\mathrm{Cu}-\mathrm{N} \text { axial } \\
\text { bond angle }\left({ }^{\circ}\right)\end{array}$ & $\begin{array}{l}\mathrm{Cu}-\mathrm{Cu}+ \\
\mathrm{Cu}-\mathrm{N}(\AA)\end{array}$ & $\begin{array}{l}\mathrm{Cu}-\mathrm{Cu}+ \\
\mathrm{Cu}-\mathrm{O}(\AA)\end{array}$ \\
\hline Compound (1) & & $1.959(2)$ to $1.965(2)$ & $2.167(2)$ & & 0.161 & $2.6143(5)$ & 88.46(9)-92.98(9) & 95.30(8)- 96.42(8) & & & 4.7813 \\
\hline Compound (2) & & $1.9474(16)$ to $1.9655(16)$ & & $2.2724(18)$ & 0.176 & $2.6691(5)$ & $87.47(6)-89.87(6)$ & & $91.47(6)-101.43(7)$ & 4.9415 & \\
\hline \multirow[t]{2}{*}{ Compound (3) } & Dimer (i) & $1.952(8)$ to $1.964(10)$ & $2.170(9)$ & & 0.160 & $2.658(3)$ & 88.2(4)- 90.9(4) & $95.0(4)-96.8(4)$ & & & 4.828 \\
\hline & Dimer (ii) & $1.950(9)$ to $1.974(9)$ & & $2.311(11)$ & 0.208 & $2.758(3)$ & 87.9(4)- 89.4(4) & & 93.9(4)- 101.0(4) & 5.0690 & \\
\hline \multirow[t]{2}{*}{ Compound (4) } & Dimer (i) & $1.948(7)$ to $1.980(6)$ & $2.155(6)$ & & 0.167 & $2.653(2)$ & $88.0(3)-91.5(3)$ & 93.9(3)- 98.4(3) & & & 4.808 \\
\hline & Dimer (ii) & $1.959(6)$ to $1.974(6)$ & & $2.301(7)$ & 0.207 & $2.7473(19)$ & $88.1(3)-89.1(3)$ & & $93.6(3)-101.4(3)$ & 5.0483 & \\
\hline
\end{tabular}


pressed disks (1\% by weight in $\mathrm{KBr}$ ) on a Shimadzu FT IR spectrophotometer.

$$
\text { Synthesis of }\left[\mathrm{Cu}_{2}\left(\mathrm{ClC}_{6} \mathrm{H}_{4} \mathrm{COO}\right)_{4}(\text { Isopropanol })_{2}\right]
$$

$\mathrm{Cu}\left(\mathrm{NO}_{3}\right)_{2} \cdot 3 \mathrm{H}_{2} \mathrm{O}(0.0352 \mathrm{~g})$ was dissolved in methanol $(25 \mathrm{~mL})$. To this solution, 4- chloro benzoic acid $(0.0391 \mathrm{~g}$,) was added and the mixture was stirred for 10 min to obtain a greenish blue solution. 2-Amino-4,6dimethyl pyrimidine AMPY (0.0391 g) was added directly into the reaction mixture (Scheme 1). The resulting greenish solution was kept for crystallisation. After 72 hours a green precipitate appeared. The precipitate was recrystallised with $20 \mathrm{~mL}$ of (1:1) isopropanol/ $\mathrm{H}_{2} \mathrm{O}$ mixture. After 2 days green crystals suitable X-ray diffraction studies were obtained.

$$
\text { Synthesis of }\left[\mathrm{Cu}_{2}\left(\mathrm{C}_{6} \mathrm{H}_{5} \mathrm{COO}\right)_{4}(\mathrm{AMPY})_{2}\right]
$$

A solution of $\mathrm{Cu}\left(\mathrm{NO}_{3}\right)_{2} \cdot 3 \mathrm{H}_{2} \mathrm{O}(0.0302 \mathrm{~g})$ in $15 \mathrm{~mL}$ Methanol was stirred over a hot plate magnetic stirrer for half an hour and benzoic acid solution $(0.03053 \mathrm{~g})$ dissolved in $10 \mathrm{~mL}$ of hot water was added to it. The mixture was stirred for additional 2 hours. A green coloured solution was formed. About $(0.03079 \mathrm{~g})$ of (AMPY) was dissolved in $10 \mathrm{~mL}$ of hot water and added to the reaction mixture. The mixture was stirred for 3 hours (Scheme 1). The resulting bluish green solution was kept for slow evaporation. Crystals were deposited at room temperature from the saturated solution. After 3 days green coloured crystals suitable for X-ray diffraction were obtained. The crystals were filtered and washed with small portions of methanol and were dried in air. The same product was obtained when the $\mathrm{CuSO}_{4} \cdot 5 \mathrm{H}_{2} \mathrm{O}$ was used, but the yield was very low.

$$
\begin{array}{r}
\text { Synthesis of }\left[\mathrm{Cu}_{2}(5-\mathrm{TPC})_{4}(\text { methanol })_{2}\right] \\
{\left[\mathrm{Cu}_{2}(5-\mathrm{TPC})_{4}(\mathrm{AMPY})_{2}\right]}
\end{array}
$$

$\mathrm{Cu}\left(\mathrm{NO}_{3}\right)_{2} \cdot 3 \mathrm{H}_{2} \mathrm{O}(0.0352 \mathrm{~g})$ was dissolved in methanol (25 mL). To this solution, 5-Chloro-thiophene-2-carboxylic acid 5-TPC $(0.0866 \mathrm{~g})$ was added and the mixture was stirred and $10 \mathrm{~mL} \mathrm{H}_{2} \mathrm{O}$ was added to obtain a green solution. AMPY $(0.03079 \mathrm{~g})$ was added directly into the reaction mixture (Scheme 1). After two days, crystals were deposited at room temperature from the saturated solution.

$$
\begin{aligned}
\text { Synthesis of }[ & {\left[\mathrm{Cu}_{2}(5-\mathrm{TPC})_{4}(\text { ethanol })_{2}\right] } \\
& {\left[\mathrm{Cu}_{2}(5-\mathrm{TPC})_{4}(\mathrm{AMPY})_{2}\right] }
\end{aligned}
$$

The structure of compound $\mathbf{4}$ inspired us to design the preparation of compound 3. For the preparation of $\mathbf{3}$ the procedure similar to that of $\mathbf{4}$ was followed, but ethanol was used in the place of methanol.

\section{Single crystal X-ray structure analysis}

Intensity data sets were collected at room temperature, on a BRUKER SMART APEXII CCD [39] area-detector diffractometer equipped with graphite monochromated Mo K $\alpha$ radiation $(\lambda=0.71073 \AA)$. The data were reduced by using the program SAINT [39] and empirical absorption corrections were done by using the SADABS [39]. The structures were solved by direct methods using SHELXS-97 [40] and subsequent Fourier analyses,

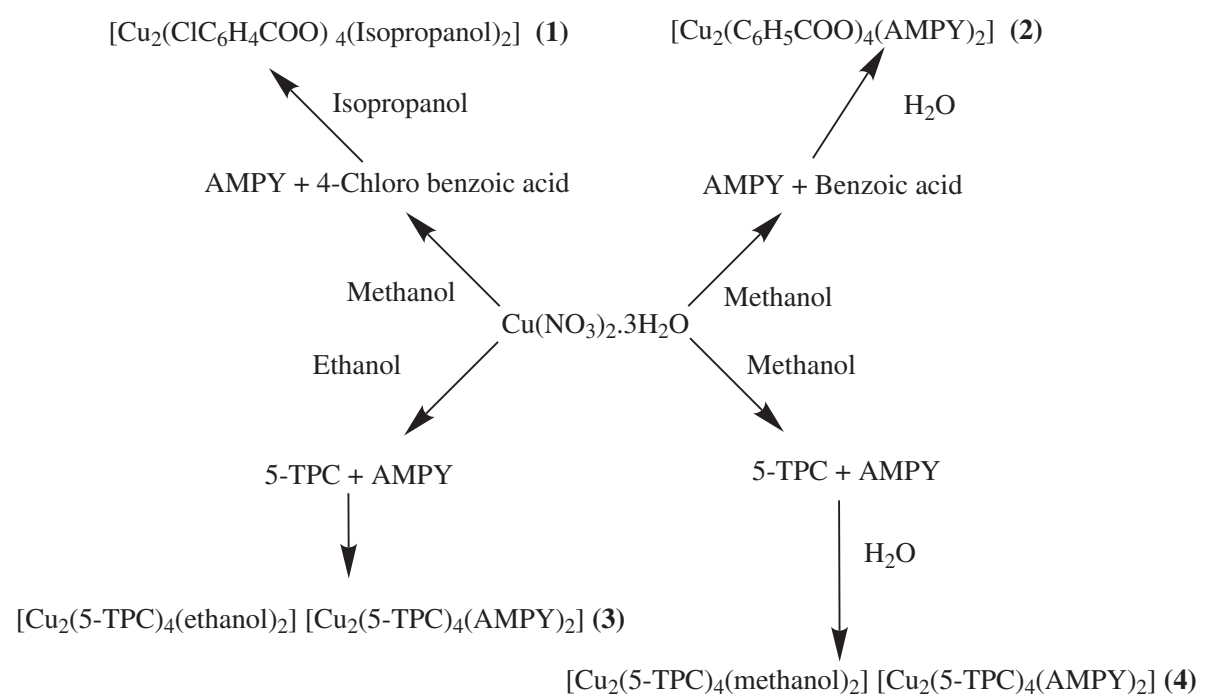

Scheme 1 Preparation of compounds (1-4). 
Table 3 Crystallographic data for compounds (1-4)

\begin{tabular}{|c|c|c|c|c|}
\hline & Compound (1) & Compound ( 2) & Compound (3) & Compound (4) \\
\hline Empirical Formula & $\mathrm{C}_{34} \mathrm{H}_{30} \mathrm{Cl}_{4} \mathrm{Cu}_{2} \mathrm{O}_{10}$ & $\mathrm{C}_{40} \mathrm{H}_{38} \mathrm{Cu}_{2} \mathrm{~N}_{6} \mathrm{O}_{8}$ & $\mathrm{C}_{56} \mathrm{H}_{44} \mathrm{Cl}_{8} \mathrm{Cu}_{4} \mathrm{~N}_{6} \mathrm{O}_{18} \mathrm{~S}_{8}$ & $\mathrm{C}_{54} \mathrm{H}_{40} \mathrm{Cl}_{8} \mathrm{Cu}_{4} \mathrm{~N}_{6} \mathrm{O}_{18} \mathrm{~S}_{8}$ \\
\hline Formula weight & 867.48 & 857.86 & 1883.33 & 1855.28 \\
\hline Temp, K & 296 & 296 & 296 & 296 \\
\hline$\lambda(\AA)$ & 0.71073 & 0.71073 & 0.71073 & 0.71073 \\
\hline Crystal system & Triclinic & Monoclinic & Monoclinic & Monoclinic \\
\hline Space group & $P-1$ & $P 2_{1} / n$ & $P 2{ }_{1} / C$ & $P 2{ }_{1} / C$ \\
\hline a $(\AA)$ & $6.6551(1)$ & $10.1209(2)$ & $16.8999(17)$ & 16.8477(3) \\
\hline$b(\AA)$ & $11.5284(2)$ & $11.3724(2)$ & $11.8885(12)$ & $11.8527(3)$ \\
\hline$c(\AA)$ & $12.4116(2)$ & $17.1914(4)$ & $19.118(2)$ & $19.0258(4)$ \\
\hline$a\left({ }^{\circ}\right)$ & $94.814(1)$ & 90 & 90 & 90 \\
\hline$\beta\left({ }^{\circ}\right)$ & 103.696(1) & $91.695(1)$ & $105.533(7)$ & $105.487(1)$ \\
\hline$Y\left({ }^{\circ}\right)$ & 100.183(1) & 90 & 90 & 90 \\
\hline$V\left(\AA^{3}\right)$ & $902.69(3)$ & 1977.85(7) & $3700.8(7)$ & $3661.33(14)$ \\
\hline Z & 1 & 2 & 2 & 2 \\
\hline$\rho$ calcd $\left(\mathrm{g} / \mathrm{cm}^{3}\right)$ & 1.596 & 1.441 & 1.690 & 1.683 \\
\hline$\mu(m m-1)$ & 1.530 & 1.135 & 1.717 & 1.734 \\
\hline$F(000)$ & 440.0 & 884.0 & 1892.0 & 1860.0 \\
\hline Crystal size (mm) & $0.15 \times 0.12 \times 0.10$ & $0.20 \times 0.18 \times 0.15$ & $0.09 \times 0.06 \times 0.05$ & $0.16 \times 0.15 \times 0.12$ \\
\hline No of reflections collected & 5830 & 4880 & 3478 & 4049 \\
\hline Number restraints & 1 & 0 & 1 & 1 \\
\hline Goodness-of-fit on F2 & 1.042 & 1.069 & 1.095 & 1.061 \\
\hline Final R1 index $[\mid>2 \sigma(l)]$ & 0.0463 & 0.0379 & 0.0651 & 0.0535 \\
\hline wR2 (all data) & 0.1254 & 0.0973 & 0.1871 & 0.1725 \\
\hline Largest difference in peak and hole $\left(e \AA^{-3}\right)$ & 1.14 and -0.96 & 0.34 and -0.45 & 1.71 and -0.54 & 1.97 and -0.55 \\
\hline
\end{tabular}

$\mathrm{R}_{1}=\sum(|| \mathrm{Fo}|-| \mathrm{Fc}||) / \sum|\mathrm{Fo}| ; w \mathrm{R}_{2}=\left[\sum w\left(\left|\mathrm{Fo}_{\mathrm{o}}\right|-\left|\mathrm{F}_{\mathrm{c}}\right|^{2}\right)^{2}\right] / \sum w\left(\left|\mathrm{Fo}^{2}\right|^{2}\right]^{1 / 2}$.

refined anisotropically by full-matrix least-squares method using SHELXL-97 [40] within the WINGX suite of software, based on $\mathrm{F}^{2}$ with all reflections. All carbon hydrogens were positioned geometrically and refined by a riding model with Uiso1.2 times that of attached atoms. All non $\mathrm{H}$ atoms were refined anisotropically. The hydrogens attached to the neutral alchol ligands (H1 in 1, H5 in 3 and 4) were located in difference Fourier maps and refined using $\mathrm{O}-\mathrm{H}$ distance restraints of 0.82 (2) $\AA$ via the DFIX command. The molecular structure was drawn using the ORTEP-III [41] and POV-ray [42]. Crystal data parameters for compounds 1-4 were summarized in (Table 3). The crystals remained stable throughout the data collection.

\section{Conclusions}

We have crystallised four dinuclear paddle wheel copper(II) complexes of types $\mathrm{Cu}_{2}(\mathrm{RCOO})_{4}(\mathrm{~L})_{2}$ and $\mathrm{Cu}_{2}(\mathrm{RCOO})_{4}(\mathrm{~S})_{2}$ $\mathrm{Cu}_{2}(\mathrm{RCOO})_{4}(\mathrm{~L})_{2}$, which retain the Copper acetate paddle wheel geometry. The compounds 1-4 contain different carboxylates, axial ligands, and solvents. The compounds 3 and $\mathbf{4}$ are co-crystals of inorganic complex with another inorganic complex which is not common. In addition to it $\mathbf{3}$ and $\mathbf{4}$ are differ only in the solvent molecule coordinated to copper atom. We have also investigated the supramolecular architectures present in the four compounds and compared their geometrical parameters. The structural results of compounds 1-4 are in good agreement with similar typed $\mathrm{Cu}$ (II) complexes with a paddle wheel geometry. The observed $(\mathrm{Cu}-\mathrm{Cu}, \mathrm{Cu}-\mathrm{O}, \mathrm{Cu}-\mathrm{N}$ distances) are comparable with that of previously reported structures. The crystal structure of $\mathbf{1}$ is stabilised by $\pi-\pi$ and $\mathrm{C}-\mathrm{H}---\pi$ interactions. The crystal structure of 2 is stabilised by $\mathrm{C}-\mathrm{H}-\mathrm{O}$ and $\mathrm{N}-\mathrm{H}-\mathrm{O}$ interactions. The crystal structures of $\mathbf{3}$ and $\mathbf{4}$ are stabilised by $\mathrm{C}-\mathrm{H}-\mathrm{O}$ and $\mathrm{N}-\mathrm{H}-\mathrm{O}$ interactions and $\pi-$ $\pi$ interactions.

\section{Competing interests}

The authors declare that they have no competing interests.

\section{Authors' contributions}

This work was prepared in the research group of PTM. He proposed the work and drafted the manuscript. SJJ participated in the design and presiding the experiments, collected the X-ray data and drafted the manuscript. Both authors read and approved the final manuscript. 


\section{Acknowledgements}

SJJ thank the UGC-SAP for the award of RFSMS. The authors thank the DST India (FIST programme) for the use of the diffractometer at the School of Chemistry, Bharathidasan University, Tiruchirappalli, Tamilnadu, India.

Received: 23 January 2013 Accepted: 13 February 2013

Published: 21 February 2013

\section{References}

1. Sundberg MR, Uggla R, Melnik M: Comparison of the structural parameters in copper(II) acetate-type dimers containing distorted square pyramidal $\mathrm{CuO}_{4} \mathrm{O}$ and $\mathrm{CuO}_{4} \mathrm{~N}$ chromophores. Polyhedron 1996, 15:1157-1163.

2. Cotton FA, Wilkinson G, Murillo CA, Bochmann M: Advanced Inorganic Chemistry. 6th edition. Singapore: John Wiley \& Sons; 1999.

3. van Niekerk JN, Schoening FRL: A new type of copper complex as found in the crystal structure of cupric acetate, $\mathrm{Cu}_{2}\left(\mathrm{CH}_{3} \mathrm{COO}\right)_{4} \cdot 2 \mathrm{H}_{2} \mathrm{O}$. Acta Cryst 1953, 6:227-232.

4. Chadjistamatis I, Terzis A, Raptopoulou CP, Perlepes SP: First use of the succinamate(-1) ligand in $3 \mathrm{~d}$-metal chemistry: dinuclear copper(II) complexes with the rare $\left[\mathrm{Cu}_{2}\left(\eta^{1}: \mu_{2}-\mathrm{O}_{2} \mathrm{CR}\right)_{2}\left(\eta^{1}: \eta^{1}: \mu_{2}-\mathrm{O}_{2} \mathrm{CR}\right)\right]^{+}$, $\left[\mathrm{Cu}_{2}\right.$ $\left.\left(\eta^{1}: \eta^{1}: \mu_{2}-\mathrm{O}_{2} \mathrm{CR}\right)_{2}\right]^{2+}$ and $\left[\mathrm{Cu}_{2}(\mu-\mathrm{OH})\left(\mu-\mathrm{OH}_{2}\right)\left(\eta^{1}: \eta^{1}: \mu_{2}-\mathrm{O}_{2} \mathrm{CR}\right)\right]^{2+}$ cores, and a novel one-dimensional polymerization of two different dimers $\left(\mathrm{R}=\mathrm{CH}_{2} \mathrm{CH}_{2} \mathrm{CONH}_{2}\right)$. Inorg Chem Commun 2003, 6:1365-1371.

5. Baranwal BP, Das SS, Singh P: Hydroxycarboxylato Complexes of Copper (II): Synthesis and Characterization. Synth React Inorg Met Org Chem 1998 28:1689-1696.

6. Baran EJ, Etcheverry SB, Torre MH, Kremer E: Preparation and properties of copper(II) sebacate. Polyhedron 1994, 13:1859-1862.

7. Campbell GC, Haw JF: Determination of magnetic and structural properties in solids containing antiferromagnetically coupled metal centers using NMR methods. Magneto-structural correlations in anhydrous copper(II) n-butyrate. Inorg Chem 1988, 27:3706-3709.

8. Kawata T, Uekusa H, Ohba S, Furukawa T, Tokii T, Muto Y, Kato M: Magnetostructural correlation in dimeric copper(II) benzoates. Acta Cryst B 1992, 48:253-261.

9. Hull JW Jr, Romer DR, Podhorez DE, Ash ML, Brady CH: Development of potential manufacturing routes for substituted thiophenes - Preparation of halogenated 2-thiophenecarboxylic acid derivatives as building blocks for a new family of 2,6-dihaloaryl 1,2,4-triazole insecticides. Beilstein J Org Chem 2007, 3:23.

10. Sharma RC, Nagar R: Synthesis and antifungal properties of some transition metal complexes involving potentially active heterocyclic ligands. Croat Chem Acta 1988, 61:849-855.

11. Lumme P, Elo H, Janne J: Antitumor activity and metal complexes of the first transition series. Trans-bis(salicylaldoximato)copper(II) and related copper(II) complexes, a novel group of potential antitumor agents. Inorg Chim Acta 1984, 92:241-251.

12. Amphlett MJ, Callely AG: The degradation of 2-thiophenecarboxylic acid by a Flavobacterium species. J Biochem 1969, 112:12-13.

13. Gogoi BK, Bezbaruah RL: Microbial degradation of sulfur compounds present in coal and petroleum. Prog Ind Microbiol 2002, 36:427-456.

14. Hemamalini M, Muthiah PT, Butcher RJ, Lynch DE: The interplay of hydrogen-bonding and metal-coordination motifs in the formation of supramolecular patterns: Copper/zinc malonates-aminopyrimidine complexes. Inorg Chem Commun 2006, 9:1155-1160.

15. Buvaylo EA, Kokozay VN, Vassilyeva OY, Skelton BW, Jezierska J, Ozarowski A: A new Cu/Zn carboxylato-bridged 1D polymer: Direct synthesis, X-ray structure and magnetic properties. Inorganica Chimica Acta 2011, 373:27-31.

16. Marinho MV, Yoshida MI, Guedes KJ, Krambrock K, Bortoluzzi AJ, Hoerner M, Machado FC, Teles WM: Synthesis, Crystal Structure, and Spectroscopic Characterization of trans-Bis [( $\mu$-1,3-bis(4-pyridyl)propane) ( $\mu$-(3thiopheneacetate-O)) (3-thiopheneacetate-O)] dicopper(II), $\left\{\left[\mathrm{Cu}_{2}\right.\right.$ $\left.\left.\left(\mathrm{O}_{2} \mathrm{CCH}_{2} \mathrm{C}_{4} \mathrm{H}_{3} \mathrm{~S}\right)_{4} \mu-(\mathrm{BPP})_{2}\right]\right\}_{n}$ : From a Dinuclear Paddle-Wheel Copper(II) Unit to a 2-D Coordination Polymer Involving Monatomic Carboxylate Bridge. Inorg Chem 2004, 43:1539-1544.

17. Lewis J, Linn C, Royston LK, Thompson RC: The chemistry of polynuclear compounds. Part III. Magnetic properties of some carboxylic acid derivatives of copper(II). J Chem Soc 1965, :6464-6477.

18. Morzyk-Ociepa B, Rozycka-Sokolowska E: Structures and spectroscopic studies of indolecarboxylic acids. Part III. Diamminetetrakis- $\mu-(\mathrm{O}, \mathrm{O} /-$ indole-3-carboxylate)dicopper(II). J Mol Str 2006, 78:69-77.
19. Morgan YR, Turner P, Kennedy BJ, Hambley TW, Lay PA, Biffin JR, Regtop HL, Warwick B: Preparation and characterization of dinuclear copperindomethacin anti-inflammatory drugs. Inorg Chim Acta 2001, 324:150-161.

20. Barooah N, Karmakar A, Sarma RJ, Baruah JB: Self-assembly through hydrogen-bonding and $\mathrm{C}-\mathrm{H} \cdots \pi$ interactions in metal complexes of $\mathrm{N}$ functionalised glycine. Inorg Chem Commun 2006, 9:1251-1254.

21. Sarma R, Karmakar A, Baruah JB: Synthesis and characterization of pyridine $\mathrm{N}$-oxide complexes of manganese, copper and zinc. Inorg Chim Acta 2008, 361:2081-2086.

22. Deka K, Sarma RJ, Baruah JB: Nitrogen-oxygen bond formation during oxidative reactions of copper(II)benzoate complexes having 3,5dimethylpyrazole. Inorg Chem Commun 2006, 9:931-934.

23. Dey SK, Bag B, Malik KMA, El Fallah MS, Ribas J, Mitra S: A Quasi-Tetrahedral Cu4 Cluster and a Helical-Chain Copper(II) Complex with Single Syn-Anti Carboxylate Bridges: Crystal Structure and Magnetic Properties. Inorg Chem 2003, 42:4029-4035.

24. Dey SK, Bag B, Zhou Z, Chan ASC, Mitra S: Synthesis, characterization and crystal structure of a monomeric and a macrocyclic copper (II) complex with a large cavity using benzylacetylacetone ligand. Inorg Chim Acta 2004, 357:1991-1996.

25. Saha MK, Dey DK, Samanta B, Edwards AJ, Clegg W, Mitra S: Synthesis, structure and magnetic properties of a mononuclear $\mathrm{Cu}(\mathrm{II})$ complex with a NNO donor Schiff base ligand and its oxalato- and oxamidato-bridged dinuclear complexes. J Chem Soc Dalton Trans 2003, :488-492.

26. Datta A, Choudhury CR, Talukder P, Mitra S, Dahlenburg L, Matsushita T: A novel doubly phenoxo-bridged $\mathrm{Cu}(\mathrm{II})$ trimer: synthesis, crystal structure and low-temperature magnetic behavior. J Chem Res 2003, 10:642-644.

27. Deacon GB, Phillips RJ: Relationships between the carbon-oxygen stretching frequencies of carboxylato complexes and the type of carboxylate. Coord Chem Rev 1980, 33:227-250.

28. Agterberg FPW, Provo Kluit HAJ, Driessen WL, Reedijk J, Oevering H, Buijs W Veldman N, Lakin MT, Spek AL: Three dinuclear copper(II) carboxylates with the paddle-wheel cage structure as intermediates in copper(II) catalyzed oxidations of carboxylic acids. X-ray crystal structures of [tetrakis(diphenyl acetato- $\mu-\mathrm{O}, \mathrm{O} /$ )bis(acetonitrile-N)dicopper(II)] tetrakis (acetonitrile), [tetrakis(diphenyl acetato- $\mu-0,0 /$ ) bis(acetone-O)dicopper (III)] and [tetrakis(1-phenyl-1-carboxylato- $\mu$-O,O/-cyclopentane)-bis (ethanol-O)dicopper(II)] bis (ethanol). Inorg Chim Acta 1998, 267:183-192

29. Riggio I, van Albada GA, Mutikainen I, Turpeinen U, Reedijk J: Catena-Poly [[bis(nitrato)(pyrimidine)copper(II)] -[mu]-pyrimidine-N:N']. Acta Cryst C 2000, 56:380-381.

30. Yasui M, Ishikawa Y, Akiyama N, Ishida T, Nogami T, Iwasaki F: Dipyrimidinecopper(II) dinitrate complexes showing magnetic interactions. Acta Cryst B 2001, 57:288-295.

31. Bora SJ, Sarmah P, Phukan P, Das BK: Tetrakis([mu]-benzoato-[kappa]20:0) bis\{[4-(dimethylamino)pyridine-[kappa]N1]copper(II). Acta Cryst C 2007, 63:392-394

32. Moncol J, Múdra M, Lönnecke P, Hewitt M, Valko M, Morris H, Švorec J, Melník M, Mazúr M, Koman M: Crystal structures and spectroscopic behavior of monomeric, dimeric and polymeric copper(II) chloroacetate adducts with isonicotinamide, $\mathrm{N}$-methylnicotinamide and $\mathrm{N}, \mathrm{N}$ diethylnicotinamide. Inorg Chim Acta 2007, 360:3213-3225.

33. Selvakumar PM, Suresh E, Subramanian PS: New macrocyclic Cu(II)bischelates with paddle wheel Cu2-acetate cage. Inorg Chim Acta 2008, 361:1503-1509.

34. Makhankova VG, BeCuischenko AO, Kokozay VN, Zubatyuk RI, Shishkin OV, Jezierska J, Ozarowski A: Direct Synthesis, Crystal Structures, High-Field EPR, and Magnetic Studies of Heterometallic Polymers Containing Manganese(II) Carboxylates Interconnected by $\left[\mathrm{Cu}(\mathrm{en})^{2}\right]^{2+}$. Inorg Chem 2008, 47:4554-4559.

35. Moncol J, Kalinakova B, Svorec J, Kleinova M, Koman M, Hudecova D, Melnik M, Mazur M, Valko M: Spectral properties and bio-activity of copper(II) clofibriates, part III: crystal structure of $\mathrm{Cu}($ clofibriate)2(2pyridylmethanol)2, Cu(clofibriate)2(4-pyridylmethanol)2(H2O) dihydrate, and $\mathrm{Cu}_{2}$ (clofibriate) ${ }_{4}(\mathrm{~N}, \mathrm{~N} \text {-diethylnicotinamide) })_{2}$. Inorg Chim Acta 2004, 357:3211-3222.

36. Kozlevcar B, Radisek M, Jaglicic Z, Merzel F, Glazar L, Golobi A, Segedin P. Strong antiferromagnetism in the dinuclear 2-pyridone complex with $\mathrm{N}$ C-O bridges: A paddle-wheel analogue of the dinuclear tetracarboxylates. Polyhedron 2007, 26:5414-5419. 
37. Youngme $S$, Cheansirisomboon $A$, Danvirutai C, Pakawatchai C, Chaichit N, Engkagul C, van Albada GA, Costa JS, Reedijk J: Three New Polynuclear Tetracarboxylato-Bridged Copper(li) Complexes: Syntheses, X-Ray Structure and Magnetic Properties. Polyhedron 2008, 27:1875-1882.

38. Ma L, Lin W: Chirality-Controlled and Solvent-Templated Catenation Isomerism in Metal-Organic Frameworks. J Am Chem Soc 2008, 130:13834-13835.

39. Bruker: APEX2, SAINT and SADABS. Madison,Wisconsin, USA: Bruker AXS Inc; 2008.

40. Sheldrick GM: Acta Cryst A 2008, 64:112

41. Spek AL: Acta Cryst D 2009, 65:148.

42. Farrugia LJ: POV-Ray - 3.5. Australia: Glasgow University; 2003.

doi:10.1186/1752-153X-7-35

Cite this article as: Jenniefer and Muthiah: Synthesis, characterization and X-ray structural studies of four copper (II) complexes containing dinuclear paddle wheel structures. Chemistry Central Journal 2013 7:35.

\section{Publish with ChemistryCentral and every scientist can read your work free of charge \\ "Open access provides opportunities to our colleagues in other parts of the globe, by allowing anyone to view the content free of charge." \\ W. Jeffery Hurst, The Hershey Company. \\ - available free of charge to the entire scientific community \\ - peer reviewed and published immediately upon acceptance \\ - cited in PubMed and archived on PubMed Central \\ - yours - you keep the copyright \\ Submit your manuscript here: \\ http://www.chemistrycentral.com/manuscript/<smiles>c1ccccc1</smiles> 